The Agent-Based Modeling Approach through Some Foundational Monographs

Author(s): Flaminio Squazzoni

Source: Revue française de sociologie (English Edition), Vol. 55, No. 4, Agent-based

Simulation: Principles and Applications to Social Phenomena (2014), pp. 827-840

Published by: Sciences Po University Press

Stable URL: http://www.jstor.org/stable/revfransocieng.55.4.827

Accessed: 15-11-2016 09:25 UTC

JSTOR is a not-for-profit service that helps scholars, researchers, and students discover, use, and build upon a wide range of content in a trusted digital archive. We use information technology and tools to increase productivity and facilitate new forms of scholarship. For more information about JSTOR, please contact support@jstor.org.

Your use of the JSTOR archive indicates your acceptance of the Terms \& Conditions of Use, available at http://about.jstor.org/terms

Sciences Po University Press is collaborating with JSTOR to digitize, preserve and extend access to Revue française de sociologie (English Edition) 


\title{
The Agent-Based Modeling Approach through Some Foundational Monographs
}

\author{
Flaminio SQUAZZONI
}

\begin{abstract}
This article reviews certain foundational monographs that underline the sociological relevance of agent-based modeling. Examples have been taken from studies on cooperation, social dynamics and norms. They show the importance of modeling complex agent behavior and interaction to understand social outcomes and why modeling and abstraction can be important for sociological investigation. Agent-based models can help us produce more consistent and verifiable theories on social phenomena and allow us to pre-arrange theories towards empirical validation and replication. Finally, this article defends the need for tighter links between behavioral science and sociology, towards a more "working together" attitude.
\end{abstract}

Key words. Agent-BAsed mOdels - Complexity - Generative explanation - Social NORMS - COOPERATION

Agent-based models (ABMs) are computer simulations of social interaction between heterogeneous agents (e.g., individuals, firms, or states), embedded in social structures (e.g., social networks, spatial neighborhoods, or institutional scaffolds) that are built to observe and analyze the emergence of aggregate outcomes. While computer simulation has roots in sociology that trace back to the 1960s (see details in the introductory essay), it was only from the 1990s that ABM applications to social phenomena reached a critical mass and gave rise to a coherent, programmatic approach. This was also thanks to the diffusion of the first open source ABM platforms, such as SWARM, which made explicitly individual behavior models possible, as well as a worldwide community of ABM modelers.

This article aims to review some foundational monographs that show the sociological relevance of ABMs. These include: The Complexity of Cooperation. Agent-Based Models of Competition and Collaboration by Robert Axelrod (1997), Generative Social Science: Studies in Agent-Based Computational Modeling by Joshua M. Epstein (2007), Complex Adaptive Systems. An Introduction to Computational Models of Social Life by John Miller and Scott E. Page (2007), Reputation in Artificial Societies: Social Beliefs for Social Order by Rosaria Conte and Mario Paolucci (2002) and Working Together: Collective Action, the Commons, and Multiple Methods in Practice by Amy R. Poteete, Marco A. Janssen and Elinor Ostrom (2010).

These books were selected from the wide-ranging ABMs literature published over the last decades, according to the influence they have had on the community (e.g., in terms of citations). Furthermore, in order to look at coherent contributions, 
only monographs have been considered here, while plenty of ABM editions from different authors have been extremely influential but without the "programmatic" coherence of the former (e.g., Gilbert and Doran 1994; Gilbert and Conte 1995; Conte, Hegselmann and Terna 1997).

Although they have their own lines of argument, these books share some common points that have important implications for sociologists. Firstly, they suggest that formalizing models to abstract social reality is fundamental to discipline theory building, promote inter-subjective dialogue and make findings testing and replication a more collective endeavor. Secondly, they show that explaining social outcomes through generative models, i.e., outcomes as consequences of agent behavior, can help us base investigation on verifiable causes (e.g., individual reasons and motivations or interaction outcomes). Thirdly, they demonstrate that it is more informative to look at social reality in terms of space-time processes, dynamics and evolution rather than as static properties of social structures. Finally, they indicate that there is no inherent isomorphism between explanandum (i.e., social complexity) and explanans (i.e., a sociological model) as the former can also be the result of simple individual behavior and interaction effects (e.g., Macy and Willer 2002).

\section{Game-theory inspired ABMs of competition and cooperation}

If we look at social reality from an evolutionary perspective, we see complex forms of cooperation and collaboration between individuals through social norms and institutions that are rarely found in other species. Blood donation, charitable trusts and mutual aid among strangers would not exist if we were not capable of overcoming free-riding and encouraging cooperation. Understanding the social mechanisms of cooperation in hostile situations, i.e., where rational individuals are not expected to collaborate, is fundamental to set-up incentives, establish institutions and promote social norms that help us achieve socially desirable outcomes. The Complexity of Cooperation. Agent-Based Models of Competition and Collaboration by Robert Axelrod aimed to examine these mechanisms in simple game-theory inspired evolutionary models.

This book was published by Princeton University Press in 1997, as a sequel to a first book, the well-known Evolution of Cooperation (Axelrod 1984), where the author started from a famous cooperation game, i.e., the Prisoner's Dilemma (PD). The PD game starts modeling a realistic scenario. Suppose you and a criminal associate have been caught while most of the evidence from the crime scene was shredded. Now, you are both kept separated in different rooms by a prosecutor, who wants to nail someone. Suppose the prosecutor says you face a year in prison and offers you a deal: If you inform on your associate, you will have a six months reduction, whereas your associate will have five years. Suppose you know that the same deal has been offered to your associate. This means that if he/she accuses you, you will have five years and he/she will have only six months. Suppose again that in case you both accuse each other, the penalty is four and a half years each. The best for both of you would be not to accuse each other and to

828, Revue française de sociologie, 55-4, 2014 
take a year each. But if you expect that your associate will cooperate with the prosecutor, what would you do to minimize your penalty?

This is only an example of a variety of social dilemmas where individual interest is at odds with social welfare. Think about states refusing to sign a climate change treaty that may reduce emissions, as this imposes severe limitations to individual consumption and requires adopting new technology for companies, or about people refusing to take care of elderly parents, as they prefer to spend time on vacation, or again about employees who refuse to share their knowledge in joint office projects as this may benefit someone else who is less talented or expert. These are all examples of this type of dilemma.

In the 1980s, R. Axelrod created an experimental PD tournament, where people were solicited to submit their best strategies in a repeated version of this game, and he reported his findings in The Evolution of Cooperation. He eventually discovered that the best strategy included these moves: starting initially to cooperate with your counterpart, then reciprocating his/her moves, i.e., defecting with a defector and cooperating with a cooperator. This direct reciprocity strategy was dubbed Tit-for-Tat and gained popularity as a mix of fairness (e.g., being cooperative in the first move) and positive/negative incentive (e.g., paying off a cooperator and punishing a wrongdoer in the following move). The message was that game repetition could favor the selection of reciprocity strategies that could reinforce good behavior over time, despite temptation for free-riding.

The Complexity of Cooperation was inspired by this approach and included a variety of examples of ABMs that looked at large scale, long-time implications of social behavior. It showed the advantages of game-theory inspired ABMs in providing simple, general and abstracted theories on social interaction in various strategic situations. The idea was to look at cooperation from an evolutionary perspective in that aggregate behavior was generated by interaction between bounded rational, adaptive agents embedded in various structures and living in selective environments. Rather than considering perfect information, maximization and rationality as in standard game theory, Axelrod modeled agents who could learn minimally from the past and from other agents' behavior. He kept the level of agent behavior simple and realistic compared with the "Olympic" assumptions of rationality, which are typical of standard game theory. For instance, the repertoire of possible behaviors included heterogeneity and normative behavior. All applications involved a contrast between the selection forces of evolution, which would drive the system towards a non-cooperation equilibrium under the Darwinian principle of the survival of the fittest, and the emergence of certain cooperation mechanisms, which could push the system towards possible cooperative equilibria.

Some applications included have given important sociological insights. Chapter 3 of The Complexity of Cooperation examined the importance of social norms in promoting cooperation. It included an extension of the two persons PD towards a $n$-person game, where selfish incentives typically outperform direct reciprocity. R. Axelrod looked at the role of costly punishment, i.e., the cost that a cooperator individually bears to punish a wrongdoer. He also developed simulations to understand the role of social punishment against individuals who refused to punish wrongdoers. This is typically a meta-norm that adds a second layer to the dilemma, i.e., cooperating or defecting in the game plus cooperating or defecting in punishing other behavior. He used examples from colonialism, racial 
discrimination and torture. Individual behavior was conceived as the result of a possible mix between rational calculation (action modification from game payoffs) and normative components (the extent to which an action is good independent of its consequence on individual payoffs). This contribution stimulated a now large stream of ABM studies on the normative foundations of cooperation, which focuses especially on understanding indirect reciprocity, including reputation as a social sanctioning mechanism (e.g., Bowles and Gintis 2013) and norm internalization (e.g., Conte, Andrighetto and Campenní 2014).

Other examples included culture dynamics (Chap. 7), the emergence of technology standards between companies (Chap. 5), the establishment of new political actors from independent actors in addition to situations where both have different power and conflicts can occur (Chap. 6). These examples added insights on the complexity of cooperation in social contexts.

The message is that while it is impossible to look empirically at the emergence of cooperation and social norms on a large scale and in the long run, ABMs can help us explore behavioral and social interaction parameters and test the evolutionary plausibility of social mechanisms of cooperation. Although it was completely ignored by mainstream game theorists, or at best reduced to an example of folk theorem such as in a famous review on Journal of Artificial Societies and Social Simulation (Binmore 1998), The Complexity of Cooperation injected more sociological realism into strategic interaction models and stimulated a look at the emergence of social behavior, norms and conventions in an evolutionary perspective. It paved the way for the so-called "experimental game theory," which is now a branch of game theory: a branch more inductive, less concerned with analytical solutions of possible existing equilibria, and based on more realistic foundations of social behavior.

In my opinion, this approach has allowed us to exploit the advantages of a game theory framework for sociologically grounded investigation. Indeed, some sociologists started to use experimental or computational game theory fruitfully to interpret social puzzles in terms of typical cooperation problems, hypothesize heterogeneous individual behavior (e.g., normative versus strategic, optimizing versus "satisfacing," adaptive versus strategic, heuristics versus predictions) adding further specifications (e.g., different types of formal institutions), explore the role of social network externalities and effects (e.g., by exploring changes in the way individuals are connected and observing propagation dynamics or situations where cooperation collapses) and identify the role of contexts and circumstances that make cooperation more or less likely (e.g., Macy and Flache 2007; Assen, Buskens and Raub 2011; Corten 2014). Furthermore, given a common interest in modeling and understanding social interaction, certain recent contributions have cross-fertilized experiments and ABMs, so that experimental findings are used to estimate behavioral parameters of $\mathrm{ABMs}$, and $\mathrm{ABMs}$ are used to extend small-scale experimental findings (e.g., Bravo, Squazzoni and Boero 2012).

Finally, the findings of The Complexity of Cooperation help us to understand the importance of looking at behavioral aspects of social behavior in order to identify micro-generative mechanisms that are responsible for social outcomes, such as cooperation, collaboration and conflict. This is also the focus of the next book.

$\overline{\mathbf{8 3 0}, \text { Revue française de sociologie, 55-4, } 2014}$ 


\section{Generative explanations with ABMs}

Generative Social Science: Studies in Agent-Based Computational Modeling by Joshua M. Epstein was published by Princeton University Press in 2006. It was the second part of a trilogy, which started with Growing Artificial Societies: Social Science from the Bottom Up (1996) written with Robert Axtell, published by the MIT Press and completed by the recent Agent_Zero: Toward Neurocognitive Foundations for Generative Social Science, which was published in 2014 by Princeton University Press. Generative Social Science is the most programmatic contribution available on the ABM approach in social sciences, as it established a set of coherent epistemological principles that explains social phenomena through ABMs. These principles revolve around the concept of "generative sufficiency." This means that explaining a social outcome means developing models that help to discover the micro-processes (in terms of individual behavior and interaction) that are sufficient to generate a macro-outcome in a computer. Other processes and conditions could explain the outcome of interest, due to empirical circumstances or alternative theoretical assumptions by other modelers, but verifying implications of micro-processes in a model can guide our understanding of the outcome. This is in common with the idea of "generative models," recently popularized by analytical sociologists (e.g., Hedström 2005).

Generative Social Science follows the same inspiration as the author's previous book. While it starts from abstraction and simplification, it also uses empirically plausible assumptions that relax excessive postulation of the rational choice model and looked at social forces of behavior, such as imitation, adaptation, social influence and norms. Examples include: the spontaneous emergence of civil violence, due to bounded rationality and social influence, the self-fulfilling and "unintended consequence" nature of the formation of political groups, the persistence of discriminative norms despite any explicit rational intention of individuals, the strength of social conventions and its relation with the bounded, adaptive rationality nature of individuals and the importance of spatial and demographic factors in influencing collaboration and cooperation among individuals. Following the same criticism of game-theory developed by R. Axelrod, Generative Social Science suggests the explanatory irrelevance of game equilibrium in typical cooperation situations and the more importance of the co-existence of multiple normative equilibria. This considers the irreducible dynamic nature of cooperative outcomes and looks at the attainment and emergence processes rather than static or dynamic convergence towards equilibria.

In short, Generative Social Science provided a simplified rationale for ABM modelers, which reduces the formalizing models of social behavior without excessively tuning sociological realism down. It raises interesting arguments on certain limitations of bottom-up explanations of social phenomena, such as the importance of top-down causation or "immergent properties," typical of normatively contextualized behavior and social cognition (e.g., Sawyer 2005; Conte 2007; Conte, Andrighetto and Campenní 2014). It also raises questions about the need for empiricism to discriminate between varying plausible micro-explanations, which could account for the same macro-level behavior (e.g., Manzo 2014). Although the book did not cover the whole spectrum of possible micro-macro social mechanisms, it provides an invaluable lesson on the importance of behavioral foundations of sociological models. It is also worth noting that in Agent_Zero, 
J.M. Epstein has extended previous examples by studying a variety of social dynamics, from disease propagation to civil wars, by focusing on emotions and social dispositions in shaping individual behavior. This helps us to understand the potential of a tighter alliance between neurosciences, behavioral and social sciences.

Finally, this alliance is of paramount importance to look at certain sources of complexity in social systems' behavior. Reasoning about social outcomes in terms of complexity helps us to consider ABMs as a method to synthesize findings from different disciplines, which are usually considered only individually. This idea links the Epstein's book to the next one.

\section{Complex social systems}

Complex Adaptive Systems. An Introduction to Computational Models of Social Life by John Miller and Scott E. Page was published by Princeton University Press in 2007. It has several overlapping issues with the previous ones. It is a brilliant and accessible introduction to the complex system approach to social phenomena where ABMs play an essential role. Together with the previous books, especially Epstein's one, Complex Adaptive Systems shows that we are used to place excessive confidence on the supposed "isomorphism" between micro- and macro-levels of complexity when looking at social behavior. Usually, we tend to believe that a complex effect, such as a collective pattern or a social structure, must have originated from a similar complex cause such as subtle, often inscrutable social forces or coalitions of interests between powerful groups or individuals. Complex Adaptive Systems gives plenty of examples where complex and unpredictable social outcomes are the result of relatively simple agent behavior, when complex interaction effects are considered.

Firstly, Complex Adaptive Systems developed concise and clear epistemological and methodological arguments as why to look at social outcomes in terms of ABMs. Models are seen as maps to understand social reality and tools to discipline thinking, foster dialogue and stimulate creativity. It considered ABMs as a means to look at socially complex forces, such as bounded, adaptive rationality, nonlinear social interaction effects, complex peer-to-peer influences and selforganized standards of conducts and behaviors in situations of decentralized coordination. Examples include the emergence of political rules, city formation, growth and dynamics, ethnic segregation patterns, public goods provision, coordination problems, the relevance of communication between individuals in social circumstances and organization decision making under different structural conditions.

Results showed the importance of looking at social complexity "in between," as the authors pointed out. This term means exploring a space between order and chaos, top-down institutional control and self-organization, as well as empirical richness and theoretical rigor. The profound non-linearity of social processes, due to mutual influence between individuals, sensitivity of social behavior to small detail and network externalities triggered by social observation and imitation, requires models capable of explicitly incorporating these complexity sources. ABMs have made this possible.

832, Revue française de sociologie, 55-4, 2014 
Although many of the book's examples are intentionally "toy models," this contribution has helped to popularize the complexity approach to sociologists. Complexity means understanding how collective behavior is generated by interaction between individuals. Unlike other natural systems, social systems add a further layer of complexity, which deals with top-down regulation (e.g., institutions, laws, policies, etc.). However, as individuals tend to react differently to top-down stimuli and policies, the importance of understanding emergent properties of social interaction is also fundamental in highly regulated systems (e.g., Squazzoni 2014).

Among these properties, we must consider important social norms, e.g., reciprocity, fairness and mutual obligations, which tend to emerge relatively spontaneously by decentralized agent interaction in many situations, e.g., online communities and social media. One of the main topics recently investigated is reputation, i.e., how socially-shared evaluations of certain attributes of individuals or organizations can emerge from decentralized information sharing between individuals in social systems. This is the topic of the next book.

\section{Reputation and social norms}

Reputation in Artificial Societies: Social Beliefs for Social Order by Rosaria Conte and Mario Paolucci was published by Kluwer Academic Publishers in 2002. It examines the role of reputation as an emergent social process through which individuals mutually share evaluations of other agents' behavior, helping them to develop decentralized, self-organized social control. Recently, reputation has attracted growing interest by academics and online reputation system managers given the fundamental importance of regulating a variety of decentralized, anonymous economic and social exchanges that now take place in e-communities and virtual markets (e.g., eBay).

Reputation in Artificial Societies also looks at two limitations of game-theory approach to social norms. First, it provides a cognitively and sociologically richer account of individual behavior, which contemplates a mix of strategic and normative dimensions involved in individual behavior. It looks at social norms as an aggregate equilibrium, as in game theory, which can more or less persist over time by "attracting" agent behavior through selection forces. However, it also views social norms as prescriptive behavior, which may have intrinsic (moral) value for individuals. Therefore, on the one hand, it touches upon a classical issue in sociology, i.e., norm internalization and transmission that makes social order possible even in relatively weakly regulated social systems. On the other hand, it relaxes the typical assumption of "pure" game theory about the "extra" game importance of common knowledge, by which players can be perfect rational as they assume that everyone else is fully rational, too. Reputation in Artificial Societies illustrates that the way people develop beliefs about other's behavior is exactly what we must understand behaviorally and sociologically, as recently recognized by behavioral, experimental game theorists (e.g., Gintis 2009).

By distinguishing "image" from "reputation," the authors suggest a processbased theory of reputation which focuses on social processes of reputation formation and transmission. These always include a reputed agent (the agent under 
judgment), a reputing agent (the agent sharing his/her opinion of the target) and a beneficiary (the agent using information shared by the reputing agent to decide whether interacting with the reputed agent or not). As is often the case, information asymmetry exists between counterparts before entering into social or economic exchange and, in many cases, the counterparts do not have direct experience or are perfect strangers. The access to social information can help individuals trust each other and risk interaction. Looking at the social process of reputation formation, maintenance and collapse is fundamental to avoid considering reputation as simply a static attribute rigidly determined by social hierarchy and status.

R. Conte and M. Paolucci developed a simple ABM that includes a cooperation dilemma where agents can follow heterogeneous behavior, i.e., self-interest, altruism and norm compliance. Their simulations show that reputation can help individuals to share the social cost of sanctioning against self-interest behavior and provide room for evolutionary stability of cooperation even in hostile conditions, e.g., when cheating is more rational and rewarding. Unlike exchanging material goods, the low cost of social information sharing in contemporary societies, which is provided by ICT scaffolds, can explain why reputation today is effective in promoting cooperation in decentralized, self-organized groups and communities.

Although not directly based on empirical data, Reputation in Artificial Societies has stimulated important empirical applications, where data on human behavior in reputational contexts were used to calibrate ABMs (e.g., Boero et al. 2010). More recent $\mathrm{ABM}$ studies have amplified this approach towards the cognitive counterpart of norms and the importance of social contexts to provide a normative meaning and signals for individuals (e.g., Conte, Andrighetto and Campenní 2014). Furthermore, constructive linkages between qualitative studies on social norms and $\mathrm{ABMs}$ were established that show that ABMs are not simply a quantitative method (e.g., Xenitidou and Edmonds 2014).

This emphasizes the importance of strengthening a "working together" attitude among behavioral and social scientists, where methods are mixed and cross-fertilized to inform our analyses of certain complex social outcomes. This is the main insight of the next book.

\section{Cross-methods for working together}

Working Together: Collective Action, the Commons, and Multiple Methods in Practice by Amy R. Poteete, Marco A. Janssen and Elinor Ostrom was published —again-by Princeton University Press in 2010. It summarizes decades of research on commons, institutional change and collective action carried out by scholars at the Workshop in Political Theory and Policy Analysis, the Center for the Study of Institutions, Population, and Environmental Change at Indiana University and the Center for the Study of Institutional Diversity at Arizona State University. Strongly influenced by governance theory and institutional regulation for commons management developed by the Nobel Prize winner E. Ostrom, Working Together provides a cross-disciplinary, cross-methodological excursus on commons that also touches important methodological problems and standards.

834, Revue française de sociologie, 55-4, 2014 
It shows the benefits of starting from a well-defined social puzzle, i.e., how to avoid "the tragedy of the commons" by developing institutions and norms that help communities self-organize for common benefit, and suggests the importance of combining disciplines. While it integrates findings from qualitative casestudies, surveys and (lab and field) experimental research, Working Together shows how ABMs can be important to understand social dynamics and processes typically found when people are called to manage a collective good. It also provides examples of empirically grounded ABMs on field and domain data, and so is directly linked to the social sciences.

Working Together helps appreciate the variety of institutional frameworks to understand and manage commons and collective goods, such as top-down authorities and rules, market forces and incentives and social norms-based community self-organization. While the first typically tends to trigger dependence and generate information asymmetry, the second can nurture self-interest and myopic decision strategies (e.g., resource over-exploitation). Finally, the last one can promote empowerment, social capital and self-confidence but heavily relies on pre-existing "functional" social norms. Working Together also helps us understand the influence of community culture and institutional diversity, as well as institutional change. Relevant empirical work is covered with comparative field studies in Tanzania and Nigeria on community-based resource management. The main findings on experimental work on commons are integrated with more traditional surveys and field studies that especially revolve around the role of face-to-face communication and behavioral heterogeneity in collective action.

Chapters 7 and 8 include examples of ABMs on collective action ranging from more abstract models to empirically grounded applications. Preceded by a short introduction to ABMs, Chapter 7 summarizes the main findings of game-theory inspired ABMs of cooperation to focus on the importance of group selection, spatial factors, reciprocity motivations and social punishment for the sustainability of a public good. It also includes examples where the emergence of institutional rules for shared resource management is explored starting from variety and heterogeneity of individual behaviors. Chapter 8 enumerates examples of empirically grounded ABMs, where certain behavioral and structural model parameters are calibrated with empirical data collected through role-game field experiments performed on real local communities. Applications focus on incomplete information and learning, conflict and co-existence of self-interest motivation and other-regarding preferences as well as the importance of trust in controlling free-riding. In most cases, ABMs have helped understand the impact of microsituational variables on collective action outcomes, e.g., group size, sanctioning cost and capabilities and degree of completeness of information. Applications show that modeling could also be considered as a means of extending micro-scale evidence towards more complex, large-scale contexts.

While Working Together is difficult reading, requiring an open mind and broad skills, it is refreshing as it provides a coherent framework for systematizing different streams of literature, reducing typical disciplinary fragmentation and methodological self-reference that penalizes our understanding of social phenomena. It also shows the advantages of starting from a puzzle rather than a discipline. 
The main lesson from all these books is that looking at social outcomes and patterns as consequences of agent behavior in interaction contexts can help us base sociological investigation on verifiable causes, such as individual behavior or interaction outcomes, which may be empirically verified. Formalized models are essential to prearrange theoretical hypotheses towards empirical validation and inter-subjective verification, which is otherwise difficult (e.g., Squazzoni 2012). They can also help us reconsider the idea that the complexity of social patterns should always reflect some complex individual cause, as in many cases social patterns can be caused by agent interaction effects over time.

While these ideas will sound familiar to any "analytical sociology" supporter (e.g., Hedström 2005; Manzo 2014), it must be said that there is still little consensus on their importance among sociologists. For example, a principal criticism is that social processes are too complex to be formalized, whether it is mathematically, computationally or even experimentally. While I believe that this is an ideological stand, the ABM idea is that modeling does not aim at reproducing reality. Modeling simply means circumscribing a reality puzzle, by clearly defining boundary conditions, formulating hypotheses of expected links and macro-consequences and testing their salience to explain the puzzle. It is worth noting that modeling is part of the endeavor we call science in any domain. Physicists model magnetic fields to understand wave propagation, molecular biologists model interactions between DNA, RNA and protein biosynthesis to examine cells' activities, socio-ecologists model human and non-human interactions in ecological systems to look at the impact of certain behavior or consumption for the sustainability of a natural resource. Nobody claims to start from realistic models. Models are used as guided theories that produce (analytic or simulated) findings to be tested empirically or experimentally. Furthermore, they can also be viewed as tools that make collaboration and mutual understanding possible.

In addition, it should be clarified that the ABM approach does not mean suggesting any individualistic methodology's absolute dominance. Modelers can also understand the impact of macro-structures over individual behavior or even better the dynamic, processual interplay among the micro- and macro-levels (e.g., Sawyer 2005; Conte, Andrighetto and Campenní 2014). This approach simply indicates that it is more appropriate for sociological investigation to start from an explicit look at individual behavior in interactional contexts. This is the only means we have to really understand the impact of social structures.

Finally, I hope that by reading these books, it will be clear that what modeling loses in terms of realism and description can be gained in terms of better understanding and explanation of social reality.

Flaminio SQUAZZONI

Department of Economics and Management University of Brescia Via San Faustino 74/B 25122 Brescia, Italy 


\section{REFERENCES}

\section{FURTHER RELEVANT INTRODUCTORY READINGS}

Gilbert, N., 2007, Agent-Based Models, London: Sage Publications.

Gilbert, N., Troitzsch, K.G., 2005, Simulation for the Social Scientist, Maidenhead: Open University Press (2nd edition).

RAILSBACK, S.F., Grimm, V., 2011, Agent-Based and Individual-Based Modeling. A Practical Introduction, Princeton, NJ: Princeton University Press.

\section{FURTHER RELEVANT ADVANCED READINGS}

Helbing, D., 2012, Social Self-Organization. Agent-Based Simulations and Experiments to Study Emergent Social Behavior, Berlin: Springer Verlag.

Manzo, G., 2009, La spirale des inégalités. Choix scolaires en France et en Italie au XXe siècle, Paris: Presses de l'Université Paris-Sorbonne.

\section{REFERENCES CITED}

Assen, Van M., Buskens, R., Raub, W., 2011, "Micro-Macro Links and MicroFoundations," Journal of Mathematical Sociology 35(1/3): Triple Special Issue.

AXElrod, R., 1984, The Evolution of Cooperation, New York, NY: Basic Books.

AXElrod, R., 1997, The Complexity of Cooperation. Agent-Based Models of Competition and Collaboration, Princeton, NJ: Princeton University Press.

Binmore, K., 1998, "Review of The Complexity of Cooperation: Agent-Based Models of Competition and Collaboration," Journal of Artificial Societies and Social Simulation 1(1). Available online at: http://jasss.soc.surrey.ac.uk/1/1/review1.html.

Boero, R., Bravo, G., Castellani, M., Squazzoni, F., 2010, "Why Bother with What Others Tell You? An Experimental Data-Driven Agent-Based Model," Journal of Artificial Societies and Social Simulation 13(3). Available online at: http://jasss.soc.surrey.ac.uk/13/3/6.html.

Bowles, S., GinTis, H., 2013, A Cooperative Species: Human Reciprocity and Its Evolution, Princeton, NJ: Princeton University Press.

Bravo, G., Squazzoni, F., Boero, R., 2012, "Trust and Partner Selection in Social Networks: An Experimentally Grounded Model," Social Networks 34(4): 481-92.

CONTE, R., 2007, "Review of Generative Social Science: Studies in Agent-Based Computational Modeling," Journal of Artificial Societies and Social Simulation 10(4). Available online at: http://jasss.soc.surrey.ac.uk/10/4/reviews/conte.html.

Conte, R., Andrighetto, G., CAmpenní, M., 2014, Minding Norms. Mechanisms and Dynamics of Social Order in Agent Societies, New York, NY: Oxford University Press.

Conte, R., Hegselmann, R., Terna, P. (eds.), 1997, Simulating Social Phenomena, Berlin: Springer Verlag.

Conte, R., Paolucci, M., 2002, Reputation in Artificial Societies: Social Beliefs for Social Order, Berlin: Springer Verlag.

Corten, R., 2014, Computational Approaches to Studying the Co-Evolution of Networks and Behavior in Social Dilemmas, Chichester: Wiley and Sons.

Epstein, J.M., 2007, Generative Social Science: Studies in Agent-Based Computational Modeling, Princeton, NJ: Princeton University Press. 
EpsteIn, J.M., 2014, Agent_Zero: Toward Neurocognitive Foundations for Generative Social Science, Princeton, NJ: Princeton University Press.

Epstein, J.M., Axtell, R., 1996, Growing Artificial Societies: Social Science from the Bottom Up, Cambridge: MIT Press, Washington, DC: Brookings Institution Press.

Gilbert, N., Conte, R. (eds.), 1995, Artificial Societies: The Computer Simulation of Social Life, London: UCL Press.

Gilbert, N., Doran, J. (eds.), 1994, Simulating Societies: The Computer Simulation of Social Phenomena, London: UCL Press.

GinTIS, H., 2009, The Bounds of Reason. Game Theory and the Unification of the Behavioral Sciences, Princeton, NJ: Princeton University Press.

Hedström, P., 2005, Dissecting the Social. On the Principles of Analytical Sociology, Cambridge, MA: Cambridge University Press.

Macy, M., Flache, A., 2007, "Collective Action and the Empirical Content of Stochastic Learning Models," American Journal of Sociology 112(5): 1546-54.

Macy, M., WiLler, R., 2002, "From Factors to Actors: Computational Sociology and Agent-Based Modeling," Annual Review of Sociology 28: 143-66.

Manzo, G. (ed.), 2014, Analytical Sociology. Actions and Networks, Chichester: Wiley and Sons.

Miller, J., Page S.E., 2007, Complex Adaptive Systems. An Introduction to Computational Models of Social Life, Princeton, NJ: Princeton University Press.

Poteete, A.R., Janssen, M.A., Ostrom, E., 2010, Working Together: Collective Action, the Commons, and Multiple Methods in Practice, Princeton, NJ: Princeton University Press.

SAwYeR, R.K., 2005, Social Emergence: Societies as Complex Systems, Cambridge, MA: Cambridge University Press.

SQuAzZONI, F., 2010, "The Impact of Agent-Based Models in the Social Sciences after 15 Years of Incursions," History of Economic Ideas 18(2): 197-233.

SQuazzoni, F., 2012, Agent-Based Computational Sociology, Chichester: Wiley and Sons.

SQuAzZoni, F., 2014, “A Social Science-Inspired Complexity Policy: Beyond the Mantra of Incentivization," Complexity 19(6): 5-13, doi: 10.1002/cplx.21520.

Xenitidou, M., Edmonds, B. (eds.), 2014, The Complexity of Social Norms, Berlin: Springer Verlag.

838, Revue française de sociologie, 55-4, 2014 
RÉSUMÉ

\section{L'approche par modèles multi-agents à travers quelques ouvrages fondamentaux}

L'article analyse quelques monographies fondamentales qui mettent en évidence la pertinence de la simulation multi-agents pour l'analyse sociologique. Ces ouvrages ont été sélectionnés au sein de travaux qui portent sur la coopération, les dynamiques sociales et les normes. Ils montrent l'importance de modéliser les comportements complexes des acteurs et leurs interactions pour comprendre les régularités sociales ainsi que les raisons pour lesquelles la modélisation et l'abstraction sont importantes pour l'analyse sociologique. La modélisation multiagents peut nous aider à produire des théories des phénomènes sociaux plus cohérentes et vérifiables et nous permet de mieux organiser les théories avant de les tester et en vue de les répliquer. Enfin, dans l'esprit d'une approche collaborative, cet article argumente en faveur du besoin de liens plus étroits entre les approches expérimentales et la sociologie.

Mots-clés. Modèles multi-AgentS - Complexité - EXPlication génÉRATIVE - Normes SOCIALES - COOPÉRATION

\section{ZUSAMMENFASSUNG}

\section{Multi-Agent-Modellen als Annäherungsmethode in einigen grundlegenden Werken}

Der Artikel untersucht einige grundlegende Monographien in denen die Relevanz der Multi-Agent-Simulation zur soziologischen Analyse nachgewiesen wird. Es handelt sich um eine Auswahl von Werken innerhalb Arbeiten zur Kooperation, zu den sozialen Dynamiken und zu den Normen. Sie zeigen die Bedeutung auf, die komplexen Verhaltensweisen der Aktoren und deren Interaktionen zu modellieren, um die sozialen Regelmäßigkeiten und die Gründe zu verstehen, warum die Modellierung und die Abstraktion für die soziologische Analyse wichtig sind. Die Multi-Agent-Modellierung kann helfen, kohärentere und prüfbare Theorien der sozialen Phänomene zu erstellen und erlaubt, besser die Theorien zu organisieren, bevor sie geprüft und repliziert werden. Schließlich argumentiert der Artikel, im Geist einer kollaborativen Annäherung, zugunsten des Bedarfs engerer Verbindungen zwischen experimentalen Annäherungen und der Soziologie.

Wörter Schlüssel. Multi-Agent-ModelLeN - KompleXITÄT - BEWIRKENDE ERKLÄRUNG SOZIALEN NORMEN - KOOPERATION 


\section{RESUMEN}

\section{El enfoque de modelos multi-agentes a través de algunas obras fundamentales}

El artículo analiza algunas monografías fundamentales que ponen en evidencia la importancia de la simulación multi-agentes, en los análisis sociológicos. Estas obras han sido seleccionadas entre los trabajos que tratan de la cooperación, las dinámicas sociales y las normas. Nos muestran la importancia de modelizar los comportamientos complejos de los participantes y de sus interacciones para comprender las regularidades sociales, así como las razones por la cuales la modelización y la abstracción son importantes para el análisis sociológico. La modelización multi-agentes puede ayudarnos a producir las teorías de los fenómenos sociales más coherentes y verificables y nos permiten organizar mejor las teorías en vista de replicarlas antes de pruebarlas. Finalmente, en un espíritu colaborativo, este artículo argumenta en favor de la necesidad de vínculos más estrechos entre los enfoques experimentales y la sociología.

Palabras claves. MODELOS MULTI-AGENTES - COMPLEJIDAD - EXPLICACIÓN GENERATIVA NORMAS SOCIALES - COOPERACIÓN 